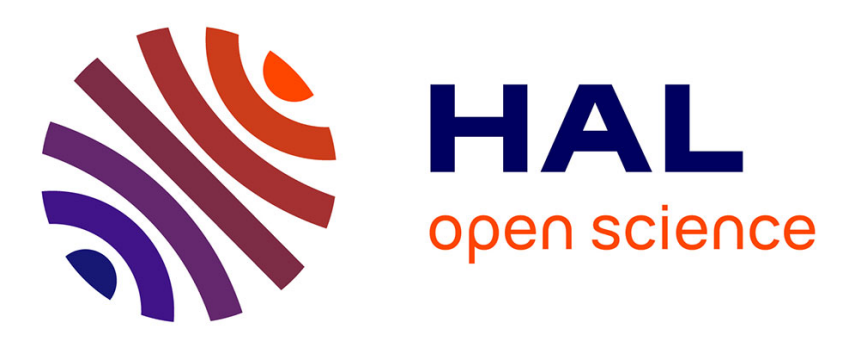

\title{
High-resolution three-dimensional tomographic diffractive microscopy of transparent inorganic and biological samples
}

Matthieu Debailleul, Vincent Georges, Bertrand Simon, R. Morin, Olivier Haeberlé

\section{To cite this version:}

Matthieu Debailleul, Vincent Georges, Bertrand Simon, R. Morin, Olivier Haeberlé. High-resolution three-dimensional tomographic diffractive microscopy of transparent inorganic and biological samples. Optics Letters, 2009, 34 (1), pp.79-81. 10.1364/OL.34.000079 . hal-00453711

\section{HAL Id: hal-00453711 https://hal.science/hal-00453711}

Submitted on 3 Oct 2013

HAL is a multi-disciplinary open access archive for the deposit and dissemination of scientific research documents, whether they are published or not. The documents may come from teaching and research institutions in France or abroad, or from public or private research centers.
L'archive ouverte pluridisciplinaire HAL, est destinée au dépôt et à la diffusion de documents scientifiques de niveau recherche, publiés ou non, émanant des établissements d'enseignement et de recherche français ou étrangers, des laboratoires publics ou privés. 


\title{
High-resolution three-dimensional tomographic diffractive microscopy of transparent inorganic and biological samples
}

\author{
M. Debailleul, ${ }^{1}$ V. Georges, ${ }^{1}$ B. Simon, ${ }^{1}$ R. Morin, ${ }^{2}$ and O. Haeberlé ${ }^{1, *}$ \\ ${ }^{1}$ Laboratoire Modélisation, Intelligence, Processus, Systèmes-EA2332, IUT Mulhouse, 61 rue A. Camus, \\ 68093 Mulhouse CEDEX, France \\ ${ }^{2}$ Centre Interdisciplinaire de Nanoscience de Marseille, UPR CNRS 318 associé à l'Université de la Méditerranée \\ et l'Université Paul Cézanne, Campus de Luminy, Case 913, 13288 Marseille CEDEX 9, France \\ *Corresponding author: olivier.haeberle@uha.fr
}

Received July 22, 2008; revised November 10, 2008; accepted November 14, 2008; posted December 3, 2008 (Doc. ID 98557); published December 24, 2008

We have developed a tomographic diffractive microscope, equipped with a fluorescence confocal scanner. We measure experimentally the lateral resolution using an edge method and by comparing tomographic images of the same samples with wide-field and laser scanning confocal microscopy images; a scanning electron microscope image serves as a reference. The experimental resolution is shown to be to about $130 \mathrm{~nm}$, or $\lambda /(3.5 \mathrm{NA})$. This instrument also permits one to measure 3D, complex index of refraction distributions, a quantity that is not accessible to conventional microscopes, and we show how this feature may be used to observe $\mathrm{KCl}$ crystals, absorption of which is very weak. (C) 2008 Optical Society of America

OCIS codes: $180.6900,090.1995,110.6960$.

Optical tomographic diffractive microscopy (TDM) [1-6] is a wavefront-reconstruction-based method [7] that allows for 3D observations of transparent objects. In digital holography, the object is reconstructed numerically. One hologram represents an object projection for one illumination angle, but, in the spatial frequency's Fourier space it has very limited support, which leads to a poor resolution. To increase the bandpass an angular scanning is performed by using various successive illumination directions, allowing for the recording of higher frequencies (synthetic aperture process in Fourier space). The hypotheses underlying the numerical reconstruction determine the accuracy of the reconstruction [8,9]. When using a filtered backprojection $[10,11]$, which does not take into account diffraction, the resolution is about the wavelength, and such an approach is limited to slowly varying index of refraction objects [3]. Conversely, a nonlinear reconstruction scheme should permit a nowadays unreached resolution in far-field (nonfluorescent) optical microscopy [12].

We have chosen an intermediate approach, based on the first Born approximation for weakly scattering objects [1]. The synthetic aperture process can be explained by expressing the solution of the Helmoltz equation in the spatial frequency's Fourier space (see $[6,13]$ for more detailed explanations), which leads to

$$
A\left(\mathbf{k}_{\mathbf{d}}\right) \propto \tilde{n}_{\delta}\left(\mathbf{k}_{\mathbf{d}}-\mathbf{k}_{\mathbf{i}}\right)
$$

where $A$ is the complex amplitude of the diffracted scalar field in the Fourier space, $\widetilde{n}_{\delta}$ is the Fourier transform of the difference between the object refractive index $n(r)$ and the average index $n_{0}, \mathbf{k}_{\mathbf{d}}$ is a diffracted wave vector, and $\mathbf{k}_{\mathbf{i}}$ is the illumination wave vector $\left(\mathbf{k}_{\mathbf{d}}=\mathbf{k}_{\mathbf{i}}=2 \pi / \lambda\right)$. The associated spatial frequencies of the scattered wave are thus located on the 2D surface of the so-called Ewald sphere and in- terpreted as a Fourier transform of the sample relative index. The absolute value of the refractive index can be measured, provided that a calibration is done. The complete angular scanning results in the "butterfly"-shaped support.

Our tomographic microscope [13,14] is inspired from the Lauer implementation [6], including a modified Mach-Zehnder setup for phase-shifting holography and a motorized tilting mirror to perform tomography. The speed is mainly limited by the slow stepby-step motors, sensitive to vibrations (a 3D image composed of 1000 holograms is obtained in $30 \mathrm{~min}$ ). Figure 1 describes the setup and recalls (in a 2D case for the sake of simplicity) the recordable, butterflyshaped frequency support [15] when the NA of the tomographic illumination is the same as the NA of the detection objective. The mirror angular scanning range is $4^{\circ}$, which translates into a tomographic scanning angle of $67^{\circ}$, thanks to the condenser. Note that holographic microscopy can be considered as a peculiar, simplified case of tomography with only one illumination angle.

In the case of a symmetric support, the Nyquist resolution is given by the inverse of the width of the frequency support [6]. For holographic microscopy (black curve), the lateral resolution is $\lambda /(2 \mathrm{NA})$. The tomographic frequency support (in gray) being twice as large as the holographic frequency support the lateral resolution is doubled to $\lambda /(4 \mathrm{NA})[2,6,13,14]$. At a wavelength of $633 \mathrm{~nm}$ and a NA=1.4 condenser and objective, the expected resolution is $113 \mathrm{~nm}$. The most striking difference is, however, the longitudinal imaging capabilities of TDM, which permits a true $3 \mathrm{D}$ imaging of transparent specimens, contrary to holographic microscopy $[13,14]$. This is easily explained by noting that the tomographic frequency support is filled, while the holographic frequency support is less extended and has a negligeable thickness. Integral 


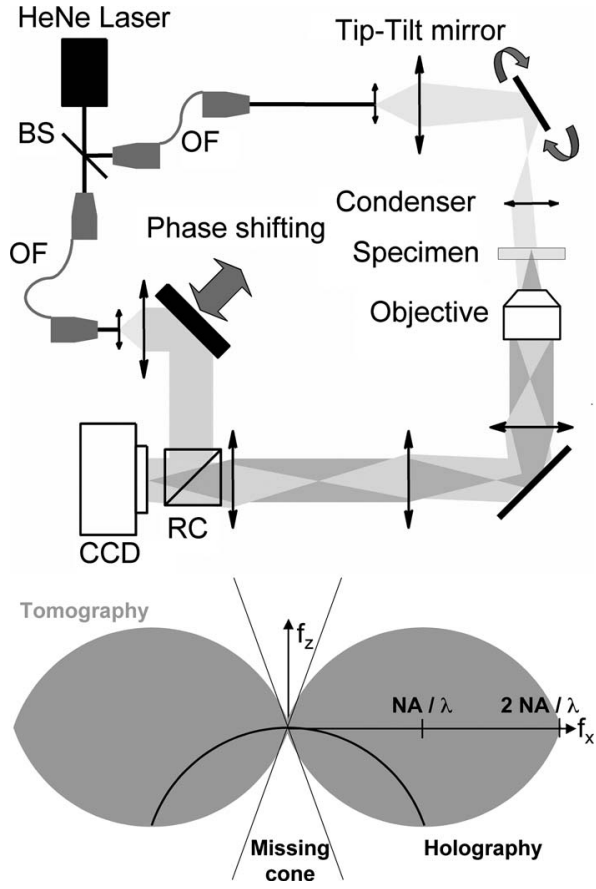

Fig. 1. Top: scheme of our tomographic diffractive microscope (BS, beam splitter; OF, optical fiber; RC, recombination cube). Scanning confocal microscopy has not been representated. Bottom, frequency support for tomographic diffractive microscopy (in gray) and holographic microscopy (black curve).

index of refraction measurements are, however, possible with holography [16].

To measure the experimental resolution of our setup, we have imaged a lacey autosupported carbon membrane. This kind of object is often used in electron microscopy and is composed of numerous carbon filaments, with sizes varying from some tens to thousands of nanometers. Such an object, with a thickness in the tens of nanometers range, is a nearly $2 \mathrm{D}$ one. It was first observed by scanning electron microscopy (SEM) to obtain a reference image and then mounted between a coverslip and glass slide for optical observations. The same condenser has been used for wide-field microscopy (WFM) and TDM, and the same objective was used for wide-field, tomographic, and laser scanning confocal microscopy (LSCM). Indeed, such an object also produces autofluorescence, which permits its confocal observation. Figure 2 displays the obtained images. The SEM image shows well-resolved and contrasted filaments. In the case of the WFM image, details are observable but the contrast is low, because of the very thin, weakly scattering specimen that is used. The LSCM (as well as the WFM) image is an average of ten images, to reduce the noise and improve the contrast, as the autofluorescence signal at the considered wavelengths is low (using an Olympus FV300 confocal head, $\lambda_{\text {exc }}$ $=543 \mathrm{~nm}$, detection above $560 \mathrm{~nm}$ ). The object is seen with much better details. The TDM image exhibits even sharper structures. But artifacts are visible: rebounds near the edges, typical from the use of the first Born approximation [17], are sometimes visible and noise is quite high, even in the low-level zones. As with WFM, TDM is based on wave scattering and

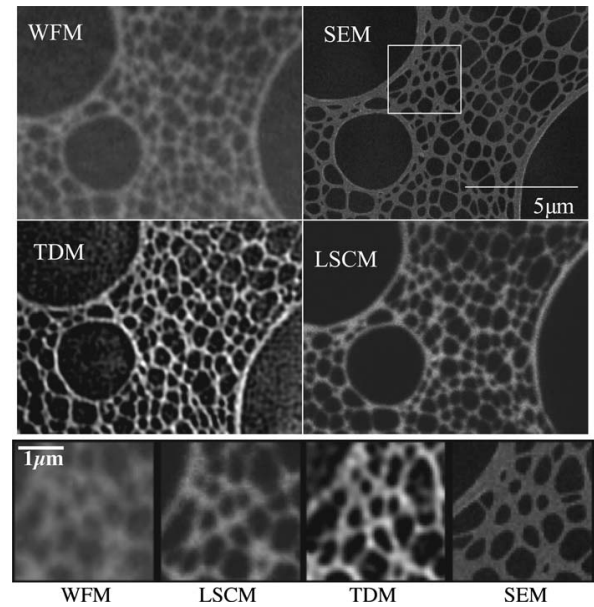

Fig. 2. Electron (SEM), wide-field (WFM), tomographic (TDM), and confocal fluorescence (LSCM) images of a lacey carbon membrane. Bottom, magnified view of the square region depicted on the SEM image.

detects a signal (the illumination) even when no specimen is present. Note, however, that while in WFM this nonscattered part can be suppressed using techniques such as oblique illumination, it is mandatory to record it to perform the tomographic reconstruction $[13,18]$. Furthermore, being a coherent imaging technique, it is sensitive to defects creating speckle. As a consequence, noise appears to be distributed all over the image, contrary to scanning techniques such as LSCM or SEM, for which noise is mostly concentrated in the higher intensity zones.

For such kinds of objects, mostly composed of filaments, the spatial resolution can be well described by the FWHM of the line spread function (LSF). A precise determination of this LSF is, however, limited by the noise and the limited sampling of the image. A more precise estimation can be obtained from the edge response function. This method was used by Choi et al. [11] to estimate the near $500 \mathrm{~nm}$ resolution of their fast tomographic setup [11]. We applied it as described by Bentzen [19] to 25 profiles using a Levenberg-Marquardt algorithm [20] for the fit.

Figure 3 presents the results for confocal and tomographic modes. Note the different noise distribu-

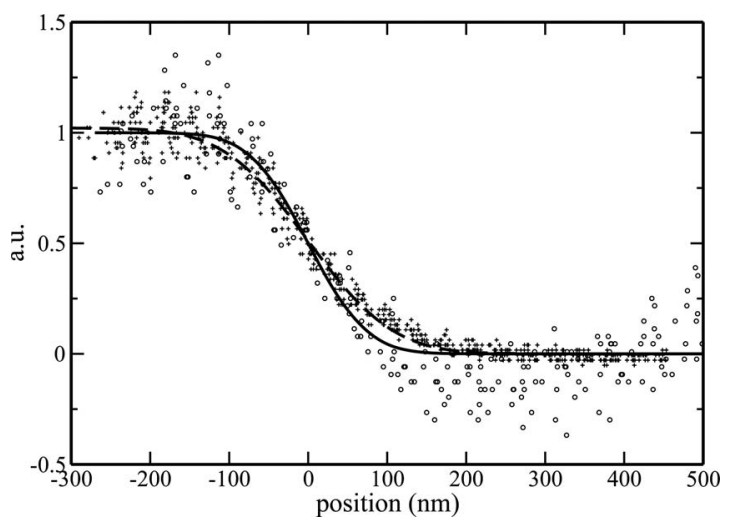

Fig. 3. Cumulative experimental edge profile data points and estimate edges profiles in LSCM (crosses and dashed curve) and TDM (circles and solid curve). 
tions, as explained previously. From the fitted profiles the method gives a lateral resolution of $129 \mathrm{~nm}$ for tomographic microscopy, slightly worse than the theoretical $113 \mathrm{~nm}$, but still much better than the $199 \mathrm{~nm}$ resolution for LSCM, which, furthermore, is obtained at a shorter wavelength. Taking into account the illuminating wavelength the experimental resolution is $\lambda /(3.5 \mathrm{NA})$, indicating that using a shorter wavelength for illumination may open the way to sub-100 $\mathrm{nm}$ imaging in far-field (nonfluorescent) transmission microscopy.

Tomographic diffractive microscopy also has interesting 3D imaging capabilities compared to holographic microscopy, as illustrated by Fig. 4, which shows $(x-z)$ views of the same pollen grain imaged with holographic, tomographic, and confocal microscopy. Note that holography, strictly speaking, is not a 3D imaging technique for transparent samples, as there is no discrimination along the $z$ axis, because of the very limited set of captured frequencies (Fig. 1). But, while having much better $3 \mathrm{D}$ imaging capabilities, our setup is a transmission microscope characterized by a so-called missing cone (Fig. 1), and it therefore still lacks the better sectioning properties of confocal microscopy (see Fig. 4 top center and top right). So one shall retain that tomographic imaging with illumination variation is characterized by an anisotropic resolution, in contrast to diffractive tomography with sample rotation, which could in principle deliver an isotropic enhanced resolution [9].

The reconstructed image represents in fact the complex index of refraction distribution within the observed specimen [1]: one measures both the index of refraction and the absorption. An interesting feature of our setup is its high sensitivity to refractive index changes. We have imaged $\mathrm{KCl}$ crystals, grown on a coverglass, and embedded within the same immersion oil as the objective. The index of refraction of $\mathrm{KCl}$ crystals has been interpolated to $n_{\mathrm{KCl}}=1.489$ at $633 \mathrm{~nm}$ from the data of [21] with negligible absorption, while the immersion oil index of refraction is given by the manufacturer (Olympus) as $n_{\text {oil }}=1.516$. Figure 4 (bottom) shows the obtained index and absorption images. These images are presented with

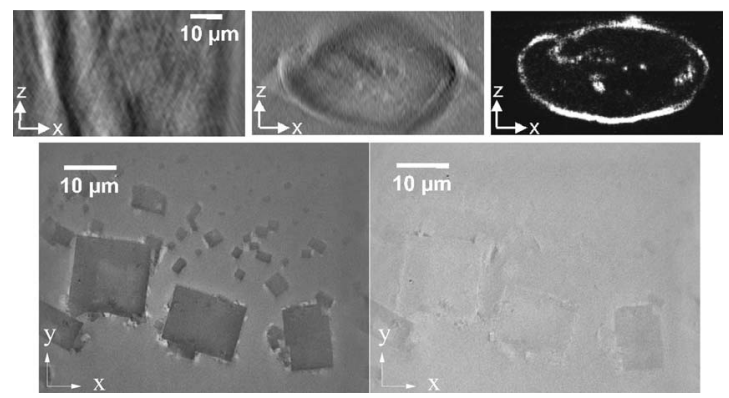

Fig. 4. Top: longitudinal $(x-z)$ views of a pollen grain. Left: holographic; center: tomographic; and right: confocal microscopies. Bottom: KCl crystals. Left: index images. Right: absorption images. eight bit gray levels, the mean value (128) representing the index of oil in the left image and the absorption of oil (set to zero) in the right images. Gray level differences represent a departure from these average values. These images are semiquantitative in the sense that linear differences translate into linear index variations [see Eq. (1)]. Despite a small index difference of 0.027, the first is well contrasted, even for the smallest crystals with sizes smaller than $2 \mu \mathrm{m}$, while the latter does not show these very thin, transparent crystals, as expected (the crystal thickness has been measured below $3 \mu \mathrm{m}$ on the $3 \mathrm{D}$ index image).

In summary, we have developed a tomographic diffractive microscope capable of imaging transparent specimens. While an absolute index of refraction calibration remains to be done, this instrument delivers $3 \mathrm{D}$, high resolution images of unprepared specimens, which should attract the interest of biologists willing to avoid fluorescence or contrast labeling techniques.

The authors thank V. Lauer for valuable discussions about tomographic microscopy.

\section{References}

1. E. Wolf, Opt. Commun. 1, 153 (1969).

2. R. Dandliker and K. Weiss, Opt. Commun. 1, 323 (1970).

3. W. H. Carter and P.-C. Ho, Appl. Opt. 13, 162 (1974).

4. A. F. Fercher, H. Bartelt, H. Becker, and E. Wiltschko, Appl. Opt. 18, 2427 (1979).

5. M. H. Malecki, A. J. Devaney, and A. Schatzberg, J. Opt. Soc. Am. A 9, 1356 (1992).

6. V. Lauer, J. Microsc. 205, 165 (2002).

7. D. Gabor, Nature 161, 777 (1948).

8. A. C. Kak and M. Slaney, Principles of Computerized Tomographic Imaging (IEEE, 1988).

9. W. Gorski and W. Osten, Opt. Lett. 32, 1977 (2007).

10. F. Charrière, A. Marian, F. Montfort, J. Kuehn, T. Colomb, E. Cuche, P. Marquet, and C. Depeursinge, Opt. Lett. 31, 178 (2006).

11. W. Choi, C. Fang-Yen, K. Badizadegan, S. Oh, N. Lue, R. R. Dasari, and M. S. Feld, Nat. Methods 4, 717 (2007).

12. A. Sentenac, P. Chaumet, and K. Belkebir, Phys. Rev. Lett. 97, 243901 (2006).

13. M. Debailleul, B. Simon, V. Georges, O. Haeberlé, and V. Lauer, Meas. Sci. Technol. 19, 074009 (2008).

14. B. Simon, M. Debailleul, V. Georges, V. Lauer, and O. Haeberlé, Eur. Phys. J.: Appl. Phys. 44, 29 (2008).

15. N. Streibel, J. Opt. Soc. Am. A 2, 121 (1985).

16. B. Rappaz, P. Marquet, E. Cuche, Y. Emery, C. Depeursinge, and P. J. Magistretti, Opt. Express 13, 9361 (2005).

17. M. Slaney, A. C. Kak, and L. E. Larsen, IEEE Trans. Microwave Theory Tech. 32, 860 (1984).

18. O. Haeberlé, A. Santenac, and H. Giovaninni, in Modern Research and Educational Topics in Microscopy (Formatex, 2007), Vol. II, p. 956.

19. S. M. Bentzen, Med. Phys. 10, 579 (1982).

20. W. H. Press, S. A. Teukolsky, W. T. Vetterling, and B. P. Flannery, Numerical Recipes in C: the Art of Scientific Computing (Cambridge U. Press, 1993).

21. H. H. Li, J. Phys. Chem. Ref. Data 5, 329 (1976). 